\title{
EFFECTS OF 4-THIAZOLIDINONE DERIVATIVES LES-2658 AND LES-1205 ON SLEEP - WAKEFULNESS CYCLE IN KINDLED RATS
}

\author{
Solomija Myronenko \\ Department of Pharmacology \\ Danylo Halytsky Lviv National Medical University \\ 69 Pekarska str., Lviv, Ukraine, 79010 \\ myronenko.solomia@gmail.com \\ Oleh Pinyazhko \\ Department of Pharmacology \\ Danylo Halytsky Lviv National Medical University \\ 69 Pekarska str., Lviv, Ukraine, 79010 \\ olehpinyazhko@gmail.com \\ Roman Lesyk \\ Department of Pharmaceutical and Bioorganic Chemistry \\ Danylo Halytsky Lviv National Medical University \\ 69 Pekarska str., Lviv, Ukraine, 79010 \\ roman.lesyk@gmail.com
}

\begin{abstract}
The research is dedicated to in-depth study of neurotrophic and antiepileptic properties of original potential anticonvulsant agents from 4-thiazolidinones - LES-2658 (5-(3-nitro-benzylidene)-2-(thiazol-2-ylimino)-thiazolidin-4-one) and LES-1205 ([2,4-dioxo5-(thiazol-2-ylcarbamoylmethyl)-thiazolidin-3-yl]-acetic acid ethyl ester), synthesized at the Department of Pharmaceutical, Organic and Bioorganic Chemistry of Danylo Halytsky Lviv National Medical University, Ukraine. Studying of sleep - wakefulness cycle characteristics in animals with chronic epileptic syndrome in conditions of 4-thiazolidinones derivatives LES-2658 and LES-1205 use was performed. The kindling syndrome was induced in Wistar rats via daily pentylenetetrazol (PTZ) (30 mg/kg, i. p.) administrations during three weeks and sleep - wakefulness cycle was studied under conditions of LES-2658 and LES-1205 administrations at doses 25.0 and $100.0 \mathrm{mg} / \mathrm{kg}$ i. p.. Total wakefulness, non - rapid eye movement sleep, rapid eye movement sleep, falling asleep latency, REM - onset latency and also number of REM sleep episodes have been determined by behavioral characteristics of experimental animals. It was established that 4-thiazolidinone derivatives Les-1205 and Les-2658 reduce REM sleep fragmentation and increase its duration in PTZ-kindled rats. Les-1205 compound at dose $100.0 \mathrm{mg} / \mathrm{kg}$ show a clear correcting influence on kindling - induced sleep disturbances.
\end{abstract}

Keywords: pentylenetetrazol kindling, sleep - wakefulness cycle, seizure syndrome, 4-thiazolidinones, diazepam.

\section{Introduction}

Epilepsy is the most common neurological disorder and its prevalence worldwide is estimated at $0.5-1 \%$ [1]. In most cases, pharmacotherapy is the only one method for satisfactory correction and control of convulsive states [2]. Despite the substantial progress in research and development of efficient anticonvulsants the search of new original anticonvulsant agents remains still open problem, especially in the context of pharmacoresistance and significant side effects under long use [3, 4].

The model of chronic epileptization of brain formed by repeated application of a subthreshold dose of pentylenetetrazol (PTZ) adequately reflects the signs of clinical forms of disease, including the disorders of sleep - wakefulness cycle [5, 6]. The study of the cycle allows estimate the brain mechanisms that control anxiety, to solve which mechanisms ensure its individual phases and to assess the influence of pharmacological agents on brain structure [5, 6]. Despite the well - es- 
tablished relation between sleep and epilepsy [7], very few studies are available on the effect of an antiepileptic drug on the sleep - cycle.

4-Thiazolidinone derivatives are promising compounds in modern pharmacology for search of potential neurotropic agents with low acute and neurotoxicity properties [8-12]. Some 4-thiazolidinones demonstrate multi-level anticonvulsant activity with satisfactory toxicity parametrs in conditions of such screening models as pentylentetrazol (PTZ, metrazol) seizures, maximal electroshock test, rotorod test [8-12]. Earlier anticonvulsant activity of original 4-thiazolidinones Les-1205 - [2,4-dioxo-5-(thiazol-2-ylcarbamoylmetyl)-thiazolidin-3-yl]-acetic acid ethyl ester and Les-2658 - 5-(3-nitrobenziliden)-2-(thiazol-2-imino)-4-thiazolidinone (synthesized at the Department of Pharmaceutical, Organic and Bioorganic Chemistry, Danylo Halytsky Lviv National Medical University) have been identified in our studies [13-16]. Until recently, the studying of influence on the sleep - wakefulness cycle characteristics in rats with chronic epileptic syndrome formed by PTZ kindling were not used for determination of 4-thiazolidinones anticonvulsant activity mechanisms.

\section{Aim of research}

The study of 4-thiazolidinone derivatives LES-2658 and LES-1205 influence on the sleep - wakefulness cycle characteristics in rats with chronic epileptic syndrome formed by pentylenetetrazol (PTZ) kindling.

\section{Material and methods}

All investigative procedures and the animal facilities were conformed to the Guide of Care and Use of Laboratory Animals within European Convention for the Protection of Vertebrate Animals used for Experimental and Other Scientific Purposes (Stratsburg: Counsil of Europe 18.03.1986) and Law of Ukraine "On protection of animals from cruelty" (21.02.2006). For the study were used 54 male rats in age 5-6 months and weight $\sim 180-220$ gr (Rattus Norvegicus Var. Alba, Wistar). The animals were divided into 7 groups: one control (intact animals) group $(n=6)$ and six experimental groups. For animals of all experimental groups the kindling syndrome was induced via daily pentylenetetrazol (PTZ) (30 mg/kg, i. p.) administrations during three weeks. Rats that the last three injections caused generalized tonic - clonic seizures were used for the experimental monitoring. The animals of experimental group I $(n=9)$ were administered $0.9 \%$ solution of $\mathrm{NaCl}$; experimental group II $(n=9)$ - animals were administered diazepam ("Gedeon Richter", Hungary), at dose $1.5 \mathrm{mg} / \mathrm{kg}$, i.p., 30 minutes before PTZ; experimental group III $(n=7)$ and IV $(n=8)$ - animals were administered LES-2658 at doses 100.0 and $25.0 \mathrm{mg} / \mathrm{kg}$ respectively, i. p., 30 minutes before PTZ; experimental group V $(\mathrm{n}=7)$ and VI $(\mathrm{n}=8)$ - animals were administered LES-1205 at doses 100.0 and $25.0 \mathrm{mg} / \mathrm{kg}$ respectively, I p., 30 minutes before PTZ. The severity of seizures was evaluated according to five-point scale [5]. The tested rats were individually continuously monitored during 4 hours after 24 hours of the last application of PTZ under free behavior conditions and with identical degree of noise and lighting. All recordings were taken between $11.00 \mathrm{a} . \mathrm{m}$. and $3 \mathrm{p}$. $\mathrm{m}$. for a total recording time of $240 \mathrm{~min}$. Total wakefulness (TW); total non-rapid eye movement sleep (NREM); total rapid eye movement sleep (REM); falling asleep latency (FAL) and REM - onset latency (RL) and also number of REM sleep episodes (RSE) have been determined by behavioral characteristics of experimental animals [6]. The durations of total wakefulness, NREM and REM sleep were given in \% compared to the overall experiment duration (100\%); FAL and RL in minutes. Data were analyzed using the statistical criteria - ANOVA + Newmann-Keuls, and Mann-Whitney U-test. All values are expressed as means \pm SEM. Differences were considered significant when: $* \mathrm{p} \leq 0.05$.

\section{Results}

The changes were observed in sleep pattern of experimental animals under kindling conditions. 


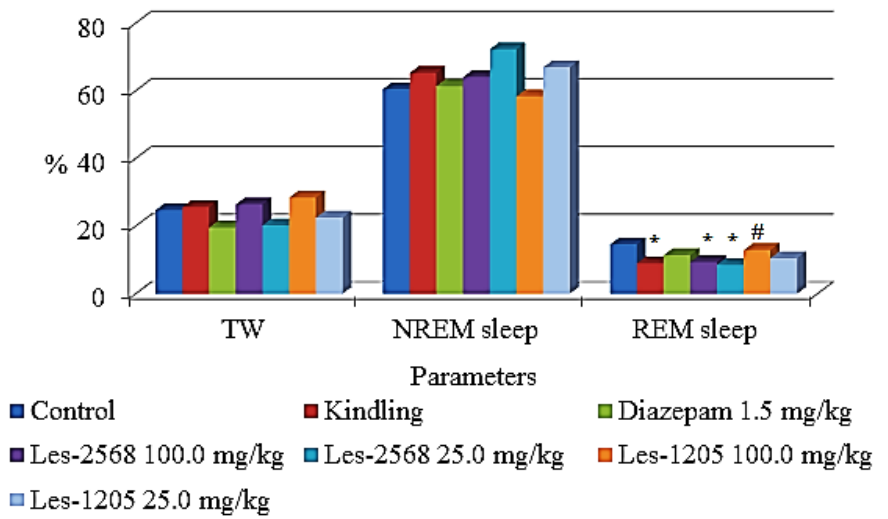

Fig. 1. The durations of total wakefulness, NREM and REM sleep under Les-2568, Les-1205 and diazepam administration in kindled rats. All parameters are given in $\%$ compared to the overall experiment duration $(100 \%) .^{*}-\mathrm{P}<0.05$ compared to the control group and $*-\mathrm{P}<0.05$ compared to the kindled animals

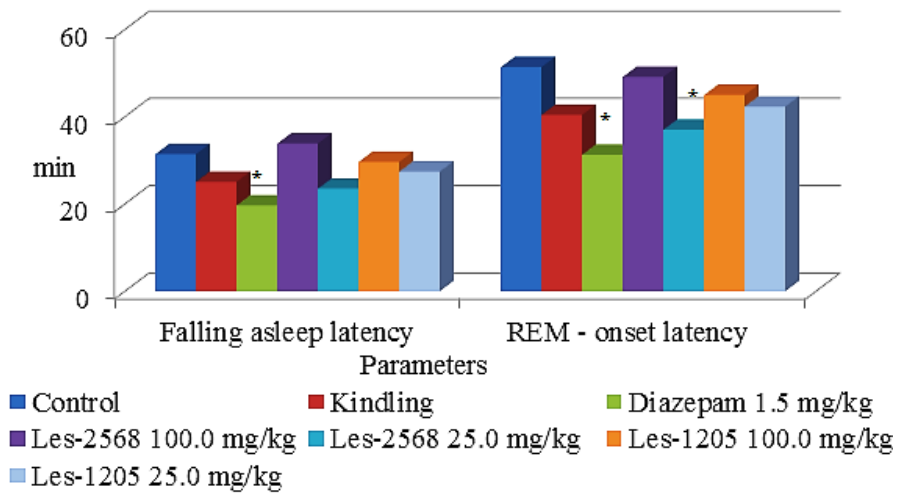

Fig. 2. The characteristics of falling asleep (FAL) and REM - onset (RL) latency under Les-2568, Les-1205 and diazepam administration in kindled rats.

* $-\mathrm{P}<0.05$ compared to the kindled animals

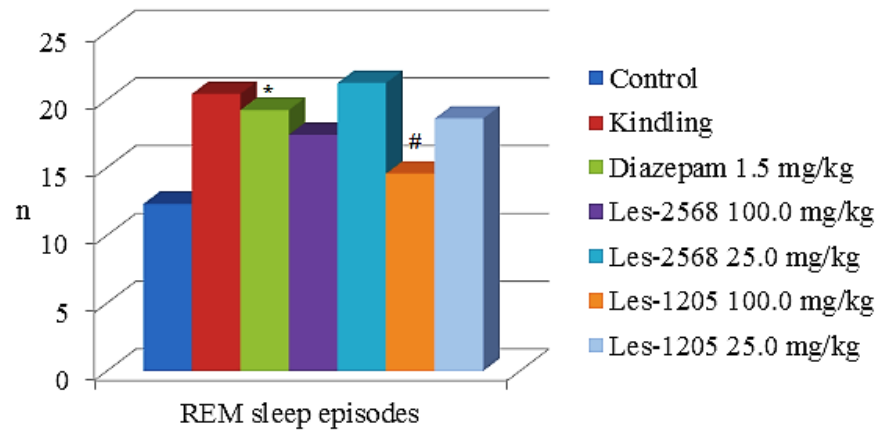

Fig. 3. The number of REM sleep episodes (RSE) under Les-2568, Les-1205 and diazepam administration in kindled rats. ${ }^{\#}-\mathrm{P}<0.05$ compared to the control group and * $-\mathrm{P}<0.05$ compared to the kindled animals

\section{Discussion}

The tendency to elongation of NREM sleep was observed in kindled rats. Its duration was $65.29 \pm 8.79 \%$ and exceeded similar in the control group by $7.9 \%(\mathrm{P}>0.05)$ (Fig. 1). At the same time, duration of REM sleep decreased by $38.4 \%$ and was $9.04 \pm 2.84 \%$ with statistically significant $(\mathrm{P}=0.015)$. Furthermore the tendency to decrease of FAL by $20.1 \%(25.1 \pm 9.48 \mathrm{~min})$ as well as of RL by $20.3 \%(40.41 \pm 13.1 \mathrm{~min}$ ) (for all $\mathrm{P}>0.05)$ was observed in kindled rats compared to 
group I (Fig. 2). Also, the number of RSE increased by $65.8 \%$ (to $20.44 \pm 5.46$ ) and was statistically significant with $\mathrm{P}<0.05$ (Fig. 3).

It was established that administration of referenced drug and tested compounds LES-2658 and LES-1205 provoke changes in the in sleep pattern of kindled rats too.

The TW period was $19.6 \pm 5.94 \%$ and decreased by $23.6 \%(\mathrm{P}>0.05)$ as well as NREM sleep duration was $61.4 \pm 7.91 \%$ and increased by $6.05 \%(\mathrm{P}>0.05)$ compared to kindled rats in rats when the diazepam was administrated at dose $1.5 \mathrm{mg} / \mathrm{kg}$, i. p.. The duration of REM sleep was $11.45 \pm 2.06 \%$ and increased by $26.6 \%(\mathrm{P}>0.05)$ but remained lower in comparison of intact rats group by $22.0 \%(\mathrm{P}>0.05)$ (Fig. 1). Also, FAL and RL were $19.69 \pm 6.48 \mathrm{~min}(\mathrm{P}=0.021)$ and $31.31 \pm 8.36 \mathrm{~min}(\mathrm{P}<0.05)$ and increased by $37.3 \%$ and by $39.1 \%$ respectively compared to the control group (Fig. 2). The number of RSE was 1.56 times higher $(19.25 \pm 4.79)$ in comparison to the intact rats group $(\mathrm{P}=0.06)$ (Fig. 3).

When the LES-2658 was administrated at dose $100.0 \mathrm{mg} / \mathrm{kg}$, i. p., duration of TW and REM sleep were $26.46 \pm 9.69 \%(\mathrm{P}>0.05)$ and $9.43 \pm 3.11 \%(\mathrm{P}<0.05)$ and increased by $3.1 \%$ and by $26.6 \%$ respectively (Fig. 1). While NREM sleep duration was $64.11 \pm 7.87 \%$ and decreased by $1.8 \%(\mathrm{P}>0.05)$ compared to kindled rats. Also, FAL and RL were $33.86 \pm 13.36 \mathrm{~min}$ and $49.14 \pm 9.82 \mathrm{~min}$ and increased by $34.9 \%$ and by $21.6 \%$ ( $\mathrm{P}>0.05$ for all) respectively (Fig. 2). While the number of RSE was $17.43 \pm 3.10$ and decreased by $14.7 \%(\mathrm{P}>0.05)$ compared to the kindled rats (Fig. 3). In case, when the LES-2658 was administrated at dose $25.0 \mathrm{mg} / \mathrm{kg}$, i. p., duration of TW was $20.25 \pm 7.43 \%$ and decreased by $21.9 \%(\mathrm{P}>0.05)$ in comparison of kindled rats (Fig. 1). While the NREM sleep duration was $72.31 \pm 6.14 \%$ and increased by $10.7 \%$ $(\mathrm{P}>0.05)$ compared to kindled rats and was higher than the same indicator in intact rats by $19.5 \%(\mathrm{P}=0.043)$. Duration of REM sleep was $8.61 \pm 2.27 \%(\mathrm{P}<0.05)$ and remained lower by $41.4 \%$ compared to the intact rats (Fig. 1).

Application of the Les-1205 at dose $100.0 \mathrm{mg} / \mathrm{kg}$ caused an increase TW duration $(28.51 \pm 8.48 \%)$ compared to kindled rats by $11.1 \%(\mathrm{P}>0.05)$ and compared to the II experimental group (diazepam used) by $45.5 \%(\mathrm{P}<0.05)$ (Fig. 1). Herewith the duration of NREM sleep phase was $58.4 \pm 9.0 \%$ and slightly decreased by $10.6 \%(\mathrm{P}>0.05)$. The duration of the REM sleep was $12.94 \pm 2.58 \%$ and increased by $43.1 \%(\mathrm{P}<0.05)$ (Fig. 1). Under these conditions, FAL and RL were $29.64 \pm 7.75 \mathrm{~min}$ and $45.0 \pm 13.06 \mathrm{~min}(\mathrm{P}>0.05$ for all) increased by $18.1 \%$ and by $11.4 \%$ respectively (Fig. 2$)$. Also, the number of RSE was $14.57 \pm 3.73$ decreased significantly by $28.8 \%$ with $\mathrm{P}<0.05$ (Fig. 3). When the Les-1205 was administrated at dose $25.0 \mathrm{mg} / \mathrm{kg}$, i. p., duration of REM sleep phase was $10.57 \pm 2.51 \%$ and increased by $16.9 \%(\mathrm{P}>0.05)$. Also, RL was $42.35 \pm 11.29$ min decreased by $8.9 \%,(\mathrm{P}>0.05)$ in comparison of II experimental group (Fig. 1, 3).

For PTZ-induced kindling model such effects as decreasing of total sleep duration and increasing of its fragmentation were characteristic. These experimental results coincide with the research of other authors $[4,17,18]$.

The use of 4-tiazolidinone derivative Les-1205 at dose $100.0 \mathrm{mg} / \mathrm{kg}$ in above-mentioned model of disorders of sleep - wakefulness cycle provoke opposite effects and is accompanied with increasing of the total sleep duration and decreasing of the number of its fragments. But for the derivative Les-2568 similar action was not observed and that can be explained by its less neurotrophic activity $[8,11]$.

Comparing of the impact of tested compounds with effects of diazepam showed that the for diazepam action was more typical reduction of FAL and RL in kindled rats and these data coincide with the results of other authors $[19,20]$. Herewith, there was not observed an influence of diazepam on the REM sleep characteristics. The total duration of REM sleep was reduced and the number of fragments increased although was not statistically significant compared to the kindled rats group. Hence, this fact is in favor for opposite action of tested compounds and diazepam upon some components of sleep - wakefulness cycle.

So, the obtained and presented results on influence of 4-thiazolidinone derivatives Les-2658 and Les-1205 on sleep - wakefulness cycle in kindled rats cannot pretend to be the full solution of the search for new anticonvulsant agents. It is an attempt of studying and understanding anticon- 
vulsant mechanisms and properties of 4-thiazolidinones as possible drug. And these results are promising for in depth-study using other different experimental seizure models.

\section{Conclusion}

1. Under developed kindling conditions the wakefulness and REM sleep phases were decreased while at one time NREM sleep phase was increased. Moreover there are reducing REM-onset latency and increasing fragmentation of REM sleep phase.

2. 4-Thiazolidinone derivatives Les-1205 and Les-2658 reduce REM sleep fragmentation and increase its duration in PTZ-kindled rats and compound Les-1205 at dose $100.0 \mathrm{mg} / \mathrm{kg}$ has been shown a clear correcting influence on kindling - induced sleep disturbances while diazepam at dose $1.5100 .0 \mathrm{mg} / \mathrm{kg}$ does not cause any corrective influence on the REM sleep of kindled rats.

3. Such ability of tested 4-thiazolidinones to recover of REM sleep parameters may indicate on importance in the implementation of anticonvulsant activity realization of this class of chemical compounds.

\section{Acknowledgment}

The authors would like to thank Dr. John L. Murphy (Anticonvulsant Screening Program, National Institute of Neurological Disordes and Stroke, National Institute of Health, Rockville, MD, USA) and specialists for specified institutions conducted in vivo testing anticonvulsant activity of the synthesized compounds. And also authors would like to thank Dr. L. Godlevsky and members of his scientific group (Odessa National Medical University, Ukraine).

\section{References}

[1] Berg, A. T., Scheffer, I. E. (2011). New concepts in classification of the epilepsies: Entering the 21st century. Epilepsia, 52 (6), 1058-1062. doi: 10.1111/j.1528-1167.2011.03101.x

[2] Perucca, P., Gilliam, F. G. (2012). Adverse effects of antiepileptic drugs. The Lancet Neurology, 11 (9), 792-802. doi: 10.1016/s1474-4422(12)70153-9

[3] Kwan, P., Arzimanoglou, A., Berg, A. T., Brodie, M. J., Allen Hauser, W., Mathern, G. et. al. (2009). Definition of drug resistant epilepsy: Consensus proposal by the ad hoc Task Force of the ILAE Commission on Therapeutic Strategies. Epilepsia, 51 (6), 1069-1077. doi: 10.1111/j.1528-1167.2009.02397.x

[4] Łuszczki, J. J. (2009). Third-generation antiepileptic drugs: mechanisms of action, pharmacokinetics and interactions. Pharmacological Reports, 61 (2), 197-216. doi: 10.1016/s1734-1140(09)70024-6

[5] Shandra, A. A., Hodlevskyy, L. S., Brusentsov, A. I. (1999). Kindling as a model of epileptic activity. Odessa: Astroprint, 276.

[6] Godlevsky, L. S., Kobolev, E. V., Mustyatsa, V. F., Drozdova, G. A. (2010). Modelling and mechanisms of suppression of epileptic syndrome. Moscow-Odessa, 350.

[7] Raol, Y. H., Meti, B. L. (1998). Sleep-Wakefulness Alterations in Amygdala-Kindled Rats. Epilepsia, 39 (11), 1133-1137. doi: 10.1111/j.1528-1157.1998.tb01303.x

[8] Myronenko, S. I., Kaminskyy, D. V., Nektegayev, I. O., Pinyazko, O. R., Lesyk, R. B. (2012). Search of new anticonvulsant agents among 4-thiazolidinones and relatedheterocyclic systems. Clinical pharmacy, pharmacotherapy and medical standardization, 1-2, 124-131.

[9] Lesyk, R., Zimenkovsky, B. (2004). 4-Thiazolidones: Centenarian History, Current Status and Perspectives for Modern Organic and Medicinal Chemistry. Current Organic Chemistry, 8 (16), 1547-1577. doi: $10.2174 / 1385272043369773$

[10] Verma, A., Saraf, S. K. (2008). 4-Thiazolidinone - A biologically active scaffold. European Journal of Medicinal Chemistry, 43 (5), 897-905. doi: 10.1016/j.ejmech.2007.07.017

[11] Bhaumik, A., Chandra, M. A., Saha, S. (2014). Synthesis, characterization and evaluation of anticonvulsant activity of some novel 4-thiazolidinone derivatives. Sch. Acad. Journal Pharmaceutical, 3 (2), 128-132. 
[12] Malik, S., Bahare, R. S., Khan, S. A. (2013). Design, synthesis and anticonvulsant evaluation of N-(benzo[d]thiazol-2-ylcarbamoyl)-2-methyl-4-oxoquinazoline-3(4H)-carbothioamide derivatives: A hybrid pharmacophore approach. European Journal of Medicinal Chemistry, 67, 1-13. doi: 10.1016/j.ejmech.2013.06.026

[13] Myronenko, S. I., Pinyazhko, O. R., Lesyk, R. B. (2015). Screening and studying of anticonvulsant activity of 4-thiazolidinones. Pharmacology and Drug Toxycology, 4-5 (45), 33-38.

[14] Myronenko, S. I., Pinyazhko, O. R. (2015). Dynamics of kindling-provoked seizures in rats under application of 4-thiazolidinones and diazepam. Achievements biology and medicine, 1, 63-67.

[15] Myronenko, S. I. (2016). Features of swimming behavior of pentylenetetrazole kindled rats under of 4-tiazolidinones and aksytynib use. Achievements biology and medicine, 1, 7-12.

[16] Myronenko, S. I., Pinyazko, O. R., Lesyk, R. B. (2016). The influence of original 4- thiazolidinone derivatives: Les-1205 and Les-2658, levetiracetam and diazepam on behaviour conditioned reflex active avoidance in rats. Pharmacology and Drug Toxycology, 4-5 (50), 27-33.

[17] Smirnov, I. V. (2008). Features of wakefulness - sleep cycle in rats in various stages of reproduction korazol kindling. Odessa Medical Journal, 2, 20-22.

[18] Schilling, M., Wetzel, W., Grecksch, G., Becker, A. (2006). Pentylenetetrazole Kindling Affects Sleep in Rats. Epilepsia, 47 (12), 2075-2082. doi: 10.1111/j.1528-1167.2006.00854.x

[19] Rudolph, U., Knoflach, F. (2011). Beyond classical benzodiazepines: novel therapeutic potential of GABAA receptor subtypes. Nature Reviews Drug Discovery, 10 (9), 685-697. doi: 10.1038/nrd3502

[20] Tan, K. R., Rudolph, U., Luscher, C. (2011). Hooked on benzodiazepines: GABAA receptor subtypes and addiction. Trends in Neurosciences, 34 (4), 188-197. doi: 10.1016/j.tins.2011.01.004 